\title{
"Esse nome nunca valerá nada": Imagem de Poe no cinema ${ }^{1}$
}

\author{
Scott Peeples ${ }^{2}$
}

Tradução:

Helciclever Barros da Silva Sales ${ }^{3}$

Emron Esplin 4

\footnotetext{
1 PEEPLES, Scott. "That Name'll Never Be Worth Anything': Poe's Image on Film". In: The Edgar Allan Poe Review, Vol. 16, No. 2 (Outono 2015), p. 169-183. Disponível em: https://www.jstor.org/stable/10.5325/edgallpoerev.16.2.0169. Acesso em: 15 de janeiro de 2019. ${ }^{2}$ Professor do College of Charleston na Carolina do Sul (EUA).

${ }^{3}$ Doutor e Mestre em Literatura e Práticas Sociais pela Universidade de Brasília (UnB). Investiga as relações intermidiáticas da obra poética de Edgar Allan Poe com as outras artes. É PesquisadorTecnologista em Informações e Avaliações Educacionais do Instituto Nacional de Estudos e Pesquisas Educacionais Anísio Teixeira - Inep. Está ocupando atualmente a Coordenação-Geral do Sistema Nacional de Avaliação da Educação Básica do Inep, gestor e guardião técnico-pedagógico responsável pelo Sistema Nacional de Avaliação da Educação Básica - Saeb e pelas seguintes Avaliações Internacionais que o Brasil faz parte: Programme for International Student Assessment (Pisa); Estudio Regional Comparativo y Explicativo (Erce); Progress in International Reading Literacy Study (PIRLS) e International Civic and Citizenship Education Study (ICCS).

Email: helciclever@gmail.com

${ }^{4}$ Doutor pela Michigan State University - MSU (2008). É Professor Assistente no Departamento de Inglês da Brigham Young University - BYU (Provo, Utah, Estados Unidos). Trabalha com estudos literários interamericanos. Seu trabalho cria intersecções entre os estudos literários comparativos e o crescente campo dos estudos da tradução. É Co-Editor do livro Translated Poe, publicado pela Lehigh University Press em 2014. Publicou ensaios sobre Katherine Anne Porter, Nellie Campobello, Pancho Villa, Edgar Allan Poe e Jorge Luis Borges. É Editor da Revista Científica Poe Studies: History, Theory, Interpretation, publicado pela Johns Hopkins University Press.

Email: emronesplin@gmail.com
} 


\section{Resumo}

O trocadilho muito usado de "Poe" e "pobre" é uma lente através da qual o autor vê retratos de Poe em filmes que variam do curta de Edgar Allen [sic] Poe, de D. W. Griffith, em 1909, à versão de 2012 de James McTeigue. Tanto as primeiras cinebiografias quanto as posteriores, nos quais Poe é descrito em um enredo fictício, baseiam-se no "meme" de Poe ao ser subestimado e desvalorizado em seu próprio tempo, apenas para ser altamente valorizado pelas gerações posteriores de leitores. Essa imagem simplificada do caráter e da genialidade de Poe corresponde ao grande valor atribuído a seu legado literário - como cópias de Tamerlane e outros poemas, itens mais valorizados por terem sido ignorados ou subestimados.

Palavras-chave: Edgar Allan Poe; Representações cinematográficas de Edgar Allan Poe; Reputação de Edgar Allan Poe.

\section{Abstract}

The well-traveled pun on "Poe" and "poor" is a lens through which the author views depictions of Poe in films ranging from D. W. Griffith's 1909 short to James McTeigue's The Raven (2012). Both early biopics and later films in which Poe is written into a fictional plot rely on the "meme" of Poe being underestimated and unappreciated in his own time, only to be valued highly by later generations of readers. This simplified image of Poe's character and genius corresponds with the great value placed on his literary remains (such as copies of Tamerlane and Other Poems), items valued more highly for having once been overlooked or underestimated.

Keywords: Edgar Allan Poe; Poe's Cinematographic representations; Edgar Allan Poe's reputation. 
Um meme da Internet amplamente divulgado reproduz uma imagem icônica de Edgar Allan Poe com as palavras "I'm just a Poe boy, nobody loves me". Um corvo em seu ombro acrescenta: "He's just a Poe boy, from a Poe family." Combinando a alusão interessante à música "Bohemian Rhapsody", da banda Queen, e uma piada muito usada (Poe/pobre), esse meme dá não apenas um excelente exemplo da presença duradoura de Poe na cultura popular, mas também uma ampla dica sobre o que impulsiona essa popularidade. De fato, o trocadilho combinando "Poe" e "pobre" pode ser o meme essencial de Poe, usando "meme" no sentido que Richard Dawkins tinha em mente quando criou o termo em 1976: uma unidade cultural distinta que é passada e que evolui ao longo do tempo - neste caso, uma alegoria ou abreviação para um mito plenamente desenvolvido ${ }^{5}$.

Amar Poe porque ele não foi amado leva a comprar Poe (na forma de uma camiseta de US\$20 representando o meme mencionado acima, ou uma cópia de Tamerlane de US\$ 662.500) porque outrora ele foi subvalorizado; eu argumentaria que essa compensação é a chave do capital cultural de Poe e foi ao longo da sua pós vida. Talvez a referência a Poe mais famosa da cultura pop - a frase lançada por John Lennon "Man you should have seen them kicking Edgar Allan Poe" de "I Am the Walrus", dos Beatles - seja uma precursora de "I'm just a Poe boy, nobody loves me", mas mesmo a frase de Lennon surgiu de uma longa tradição de considerar Poe como alguém que foi chutado apenas para ser recompensado postumamente - por exemplo, por ter seu rosto aparecendo na capa do álbum de referência dos Beatles, Sgt. Pepper's Lonely Hearts Club Band. No final do século XIX, Poe já era notoriamente subestimado, ou pelo menos famoso por ter sido subestimado em sua vida. No livro de 1886 Letters to Dead Authors, Andrew Lang diz a Poe: "Você, eu acho, é o único exemplo de um profeta americano quase sem honra em seu próprio país", mas ao mesmo tempo ele afirma: "É impossível estimar as recompensas que teriam caído para Edgar Poe, se o acaso o tornasse o contemporâneo de Mark Twain" ${ }^{\text {. Julian }}$ Hawthorne, em seu esboço de 1891 "My Adventure with Edgar Allan Poe", também tem o prazer de contar um "ressuscitado" Poe sobre o proprietário de um manuscrito de "The Murders in the Rue Morgue" que não estaria disposto separar-se dele por US\$1.000. Poe poderia esperar receber um dólar por palavra em 1891: "Além da sensação extraordinária que seria causada pelo seu reaparecimento, você ainda está

\footnotetext{
${ }^{5}$ Segundo Dawkins (2006), "Exemplos de memes são músicas, ideias, slogans, moda de roupas, maneiras de fazer potes ou de construir arcos. Assim como os genes se propagam no conjunto genético passando corpo para corpo através de espermatozoides ou óvulos, os memes se propagam no conjunto de memes passando de cérebro em cérebro através de um processo que, no sentido lato, pode ser chamado de imitação".

${ }^{6}$ Ver: LANG, 1968
} 
muito acima do nível dos escritores comuns quanto nos anos quarenta. Duvido que alguém vivo poderia rivalizar com o seu estilo de prosa"7.

Nesta redação, examino um elemento na evolução do meme "pobre / Poe": várias representações de filmes que enfatizam essa discrepância entre a negligência e a pobreza que Poe experimentou na vida e o alto valor colocado em seu trabalho postumamente. Certamente, o "mito" de Poe ter sido pobre e desvalorizado em sua vida não é falso: enquanto ele não era pouco conhecido por seus contemporâneos, Poe viveu na pobreza a maior parte de sua vida adulta, enquanto escrevia poemas e histórias que acabariam por torná-lo um dos escritores mais populares do mundo. No entanto, estou interessado nas maneiras pelas quais o núcleo da verdade é isolado e ampliado, e às vezes embelezado, pois se torna crucial para a popularidade de Poe, fornecendo um denominador comum para as diversas histórias contadas sobre 0 escritor.

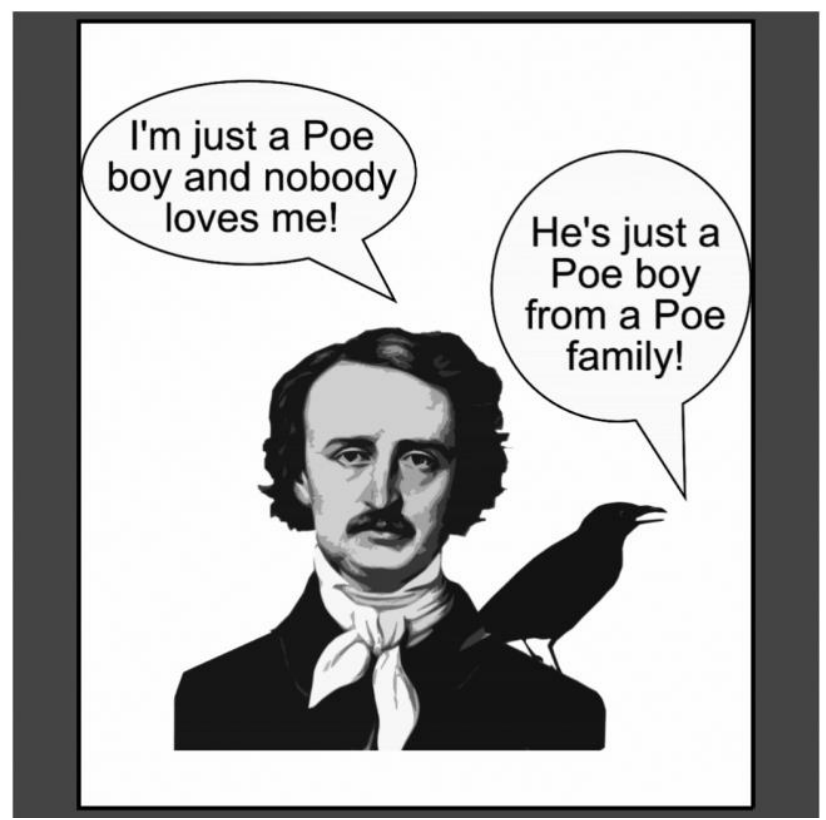

Figura 01 - Meme da Internet, design de camiseta da Antigraph.

Fonte: Cortesia de Zazzle.

Desde sua morte, os biógrafos têm se esforçado para explicar a incapacidade de Poe de ganhar uma vida decente com seus escritos e um lugar de honra reconhecido no panteão de autores americanos; e, quando eles não se esforçaram, ofereceram explicações simplistas. Eles avaliaram o significado de fatores, incluindo a suposta

\footnotetext{
${ }^{7}$ Ver:HAWTHORNE, 1969.
} 
mesquinhez do público leitor pré-guerra civil, a falta de direitos autorais internacionais eficazes, o mercado literário corrupto, a doença de Virginia Poe e o alcoolismo de Poe. Os filmes mostrando Poe - ambos cinebiografias e filmes de ficção nos quais Poe é personagem central - também oferecem explicações, enquanto retornam consistentemente à garantia de que Poe não poderia ser apreciado em seu próprio tempo, que apenas uma geração mais iluminada (a de público do filme) poderia reconhecer sua genialidade.

A mais antiga apresentação cinematográfica de Poe, Edgar Allen [sic] Poe, de DW Griffith (1909), com sete minutos de duração, estabeleceu uma tradição de confundir a morte de Virginia com a escrita e a venda de "The Raven" de Poe ${ }^{8}$. Inspirado pela aparição repentina de um pássaro preto (que surge literalmente no busto de Pallas, sem voar por dentro), Poe escreve ao lado da cama de Virginia, mostrando-lhe com entusiasmo seu trabalho. Ele então sai às pressas para vender o poema, apenas para ser rejeitado por três editores antes de encontrar um leitor compreensivo que o pague na hora.

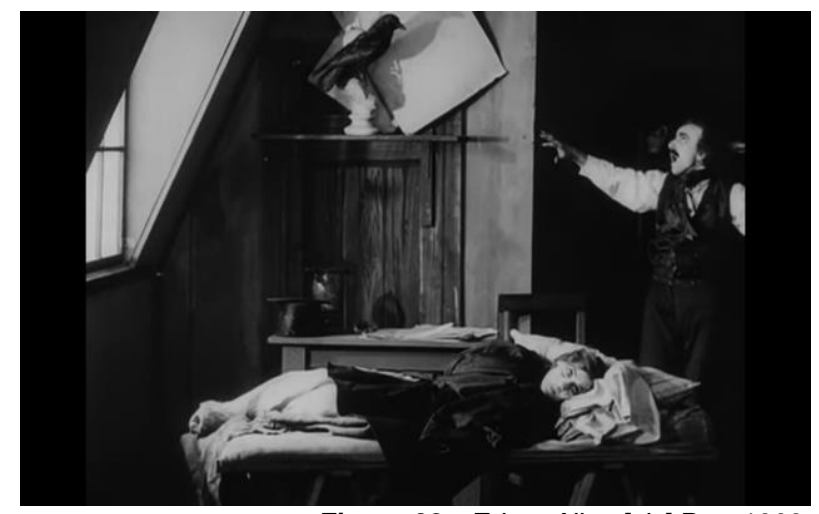

Figura 02 - Edgar Allen [sic] Poe, 1909.

Poe beija o dinheiro e é visto novamente voltando ao lado de Virginia com uma cesta de mantimentos e um cobertor. O filme termina quando ele descobre que Virginia já morreu. O filme incrivelmente comprimido de Griffith entrelaça o infortúnio de Poe com sua arte: a aparência do corvo simboliza a morte que se aproxima de Virginia e inspira o poema de Poe; o poema se torna então uma fonte potencial de sua salvação, mas como as rejeições atrasam seu retorno; seus esforços heroicos são frustrados. Uma variação mais prolongada e inferior desse cenário aparece no filme The Raven (1915), de Charles Brabin, baseado vagamente na peça teatral e no romance de George

${ }^{8}$ D. W. Griffith, dir., Edgar Allen [sic] Poe, 1909, Griffith Masterworks 2: The Avenging Conscience (DVD, Kino International, 2008). 
Hazelton - que, por sua vez, baseavam-se vagamente nos fatos da vida de Poe ${ }^{9}$. Como no curta de Griffith, o Poe de Brabin é visitado por um corvo, que serve mais como um presságio de dor futura do que inspiração para um poema. Com a visita do corvo, Brabin essencialmente encena o poema com Poe como narrador, inserindo versos selecionados em intercâmbios ao longo do percurso. Durante essa encenação alucinatória, auxiliada pela dupla exposição, Poe enfrenta o perigo do vinho (um copo se transforma em um crânio humano) e é excluído do portão do céu, antes de finalmente seu corpo e alma se separarem (sua alma permanece literalmente no chão, onde "Será levantada-Nunca mais!"). Brabin então corta para uma cena "alguns anos depois" na Fordham cottage, na qual "Edgar Poe, depois de se esforçar em vão para vender seus manuscritos, está em extrema pobreza e com espírito partido". Depois que Virginia fica doente, Poe se aventura numa noite fria para vender seus manuscritos. Nesse filme, ele falha em vender seu trabalho, mas retorna antes que Virginia morra; no entanto, como Edgar Allen [sic] Poe, The Raven destila a tragédia da vida de Poe, vinculando sua obra mais famosa, sua rejeição por seus contemporâneos e a morte de sua esposa ${ }^{10}$.

Thomas Carlson vê esses dois primeiros filmes de Poe, assim como, The Raven, um filme perdido de 1912, e The Avenging Conscience (1915), de Griffith, que mistura elementos da biografia de Poe em um enredo sugerido principalmente por "The Tell-Tale Heart', como uma continuação dos esforços de biógrafos do século XIX, como John Henry Ingram e William Gill, para resgatar a reputação de Poe. "Em nenhum lugar desses filmes", observa Carlson, "vemos o escritor apaixonado, o réprobo moral evocado por Griswold e reconhecido até por muitos dos defensores de Poe durante as acaloradas batalhas biográficas do século anterior. Os filmes nos oferecem, em vez disso, um retrato simpático de um artista atormentado por sua genialidade e vitimado pelas circunstâncias - isto é, pela doença de sua esposa e pela crueldade dos negócios

\footnotetext{
${ }^{9}$ Charles Brabin, dir., The Raven (A Romance of Edgar Allan Poe by George C. Hazelton. Founded upon Mr. Hazelton's Widely Known Novel and Play), Essanay, 1915 (DVD, Televista, 2007). O filme é episódico a ponto de não ser linear, embora cada episódio ocorra mais tarde na vida de Poe do que o anterior. Por exemplo, Sarah Helen Whitman éapresentada no final do filme, mas ela e o escritor nunca se encontram. É possível que parte do filme tenha sido perdida. Ver: SMITH, 1999, p. 18-22. Para uma descrição da peça de Hazelton e seus imitadores, veja PEEPLES, 2004, p. 128-132.

${ }^{10}$ A tuberculose de Virginia Clemm se tornou evidente para Poe pela primeira vez em janeiro de 1842, quando ela estourou um vaso sanguíneo enquanto cantava (OSTROM, POLLIN e SAVOYE, ed., 2008). "The Raven" foi publicado pela primeira vez em 29 de janeiro de 1845, mais de um ano antes de Poe se mudar de Manhattan para Fordham e quase exatamente dois anos antes da morte de Virginia. Há um relato - de Horace Wemyss Smith - de Poe ter tentado vender uma versão inicial de "The Raven" para George Rex Graham da Graham's Magazine. Smith alega ter "levado [a Poe] quinze dólares, contribuídos por Graham, Godey, McMichael e outros, que condenaram o poema, mas deram o dinheiro como caridade". A história de Smith, relacionada a Joseph Rosenbach para um artigo de jornal em 1887, parece ser a fonte da história popularizada por Hazelton, Griffith e Brabin, que Poe se esforçou para encontrar um editor para "The Raven" enquanto Virginia estava morrendo. A coleção continuada por homens que "condenaram" o poema é incorporada em The Loves of Edgar Allan Poe. Em contraste com todas essas apresentações de filmes, Smith relata que Poe foi logo "encontrado em estado de intoxicação na rua Decatur" (JACKSON e THOMAS, 1987: 437).
} 
editoriais". Carlson identifica corretamente o Poe desses filmes como um "Poe azarão domesticado, gênio conturbado e cuidador altruísta"11.

Embora esteja fora do escopo cronológico do estudo de Carlson, o filme de 1942 The Loves of Edgar Allan Poe, dirigido por Harry Lachman, pode ser visto como a apoteose do trabalho cultural de branqueamento realizado pelas primeiras cinebiografias de $\mathrm{Poe}^{12}$. Como o título sugere, o filme tem foco em um triângulo romântico, os dois "amores" sendo Virginia Clemm Poe e Elmira Royster Shelton. A rivalidade das duas mulheres permanece relativamente educada: se bem que Poe esteja perturbado em saber, depois de seu casamento com a Virginia, que Elmira ainda o ama e que seus próprios planos de casamento anteriores foram frustrados por seus pais, ele sinceramente ama Virginia e permanece fiel até depois da morte dela. The Loves oferece algumas surpresas aos estudantes da biografia de Poe: entre eles, Thomas Jefferson lê "The Gold-Bug" (publicado em 1843) enquanto Poe está cursando a Universidade da Virginia (em 1826) e, em seguida, oferece conselhos inúteis ao autor sobre como lidar com seu pai adotivo, John Allan; Rufus Griswold, como editor do Broadway Journal, rejeita "The Raven", mas não tem interação com Poe de outra maneira; e Virginia interpretada por Linda Darnell, dezoito anos na época e prestes a ser uma pin-up durante a Segunda Guerra Mundial - não podia ser confundida com a garota de treze anos que Poe considerava uma irmãzinha no início de seu relacionamento. No entanto, essas imprecisões óbvias contribuem menos para limpar a imagem de Poe do que a ênfase do filme em sua integridade e genialidade não reconhecidas. Não obstante seu sucesso com as mulheres, Poe é mais uma vez o talentoso azarão, lutando por sua própria visão artística e pela causa dos direitos autorais internacionais.

Sim, direitos autorais internacionais. Na vida real, Poe fez um editorial para proteção de direitos autorais e citou a falta de direitos autorais internacionais como base para a exploração de autores no esboço "Some Secrets of the Magazine Prison-House". Mas a proteção dos direitos autorais dificilmente foi uma cruzada ao longo da carreira e, como Meredith McGill demonstrou, Poe dedicou mais energia para fazer a "cultura da reimpressão" funcionar em sua vantagem do que para protestar contra seus efeitos ${ }^{13}$. Em The Loves, no entanto, Poe quase perde o emprego no Southern Literary Messenger por causa da questão, e ele perde o emprego na Graham's quando Charles Dickens,

\footnotetext{
${ }^{11}$ Embora uma pesquisa completa dos retratos de Poe no filme incluiria The Avenging Conscience, não a debato neste ensaio. Apesar do fato de o sobrinho sem nome revelar-se Poe nos minutos finais do filme, até aquele momento ele tem pouca semelhança biográfica com Poe; ele se parece mais com o narrador de "The Tell-Tale Heart," e, em menor grau, "TheBlack Cat." Eu vejo isso como um chamariz acrescentado, em vez de uma tentativa verdadeira de retratar Poe. Ver: CARLSON, 1998.

12 Harry Lachman, dir.: The Loves of Edgar Allan Poe (20th Century Fox, 1942).

${ }^{13}$ Ver: MCGILL, 2003 - especialmente o capítulo 4, "Unauthorized Poe".
} 
visitando a redação, o incita a uma discussão com George Rex Graham sobre o mesmo tema. Tendo perdido essa editoria, Poe se muda para Nova York, onde, dizem, "por causa de sua luta incessante contra leis injustas de direitos autorais, nenhum editor 0 contrataria e poucos dariam a seus escritos a atenção que mereciam". É claro que a sugestão de que Poe estava na lista negra por defender direitos autorais internacionais é falsa, mas serve à narrativa mais ampla do heroísmo de Poe no filme, pois luta não apenas por seu próprio reconhecimento, mas também em nome de todos os escritores. Enquanto o filme de Brabin referenciou o problema com a bebida de Poe como um obstáculo a ser superado, The Loves torna suas consequências mais explícitas, pois as binges contribuem para a perda da editoria do Messenger e sua morte. E, no entanto, Lachman saneia 0 alcoolismo de Poe, principalmente evitando imagens de comportamento de embriaguez e cortando até as consequências: Poe já desmaiado de ressaca ou expressando seu remorso a Virginia. Além disso, as bebedeiras de Poe sempre seguem crises fora da sua própria autoria: um confronto inesperado com o marido ciumento de Elmira, a perda do emprego na Graham's e, finalmente, a morte de Virginia. Leva apenas dois minutos do tempo do filme para ir da cena da morte dela para a de Poe; sua rápida espiral descendente leva a ser vitimado por "cabos eleitorais" que o sequestram, o pregam com álcool e o forçam a votar repetidamente em seus candidatos (invocando a popular, mas não comprovada teoria de "cooping" para o desaparecimento e a morte de Poe $)^{14}$.

Mas a cena climática do filme é paralela ao Edgar Allen [sic] Poe, de 1909, quando Poe tenta vender "The Raven" enquanto Virginia está morrendo no Fordham cottage. Como uma maneira de completar a narrativa, a agora viúva (e rica) Elmira visita à casa de Poe para oferecer ajuda, tendo ouvido falar da doença de Virginia e dos problemas financeiros da família, mas Virginia se recusa orgulhosamente a aceitar ajuda. Em cenas alternadas, Rufus Griswold, tendo dito a Poe que não achava que "The Raven" suplicaria a seus leitores, pede que sua equipe de impressoras ouça Poe recitar o poema e aconselhá-lo. Poe entrega "The Raven" com uma dor sincera em sua voz, mas os impressores, exceto um jovem assistente de olhos arregalados, parecem confusos com isso, e Poe, desencorajado, começa sua longa caminhada para casa. Nesta versão, porém, os impressores fazem uma arrecadação para ajudar Poe e enviam o rapaz atrás dele com dinheiro. Poe volta para casa carregando uma cesta de mantimentos - até a própria cesta lembra o adereço do filme de Griffith - a tempo de declarar seu amor por Virginia mais uma vez antes dela morrer. Como tem sido o caso

\footnotetext{
${ }^{14}$ Ver: QUINN (1998). Para mais informações sobre as circunstâncias da morte de Poe, ver PEARL (2006 e
} 2007). 
ao longo do filme, a pureza de Poe - expressa através de seu poema e sua devoção à Virginia - diverge com, e é vítima de um sistema de valores corrupto, enraizado na ganância. Mais cedo no filme, ele perdeu seu primeiro amor, Elmira, porque seu pai adotivo informou Royster que Poe não traria nenhuma parte da fortuna da família Allan ao casamento. Mais tarde, Poe repreende seu empregador, Thomas White: "Dinheiro, dinheiro - é tudo em que você sempre pensa". E depois que Graham o despede, Virginia oferece este reconforto: "Quem cria sempre foi tratado assim por aqueles que não entendem". Essa segunda categoria inclui praticamente todos os homens adultos que Poe encontra em The Loves, de John Allan a Griswold.

No entanto, enquanto Poe despreza o amor ao dinheiro, ele acredita que seu trabalho literário tem um valor monetário que simplesmente ainda não foi reconhecido. Ainda estudante universitário, ele tenta pagar uma dívida de jogo de US\$180 com um manuscrito que ele afirma que valerá três vezes esse valor. "É um poema", explica ele ao estudante jogador confuso, "um dos muitos que me farão famoso e rico". O suposto beneficiário revida: "Nem grandes poemas pagam dívidas no jogo", o que leva a uma briga de socos. Em torno de sua solidária família de Muddy Clemm e Virginia, Poe mostra confiança sobre os preços que seus poemas renderão (há poucas referências a histórias); ele finge que a comida que comprou com a caridade dos impressores veio da venda de "The Raven". Na cena final do filme, a narração de voz reivindica Poe afirmando não seu desafio ao comércio, mas a fama e fortuna que ele ganharia postumamente: "Mal sabiam as pessoas da época que um dia a estátua de Edgar Allan Poe ficaria no Hall da Fama ${ }^{15}$. E mal eles sabiam que o manuscrito de 'The Raven', que ele tentou em vão vender por vinte e cinco dólares, anos depois traria o preço de dezessete mil dólares de um colecionador. Os deuses riem e Poe ri com eles".

Embora o filme de Lachman cite a venda de um manuscrito "Raven", a ênfase no valor monetário de Poe foi provavelmente inspirada pelos altos preços pagos por cópias de Tamerlane e Other Poems nas décadas de 1920 e 1930. A existência da coleção de Poe, de 1827, era desconhecida até 1860, e em 1925 apenas quatro cópias haviam sido descobertas. Mas naquele ano, Vincent Starrett, mais conhecido como autor de The Home Life of Sherlock Holmes, publicou um artigo no Saturday Evening Post intitulado "Have You a Tamerlane in Your Attic?" descrevendo o frenesi que ele poderia criar contando casualmente a conhecidos sobre a existência de um panfleto antigo (que todos supõem estar escondido no seu sótão), agora valendo pelo menos US\$10.000:

${ }^{15}$ Poe foi introduzido no Hall of Fame for Great Americans na New York University - agora parte do campus do Bronx Community College - em 1910. Sua exclusão nos dois primeiros anos de votação, em 1900 e 1905, causou alguma controvérsia. The Loves of Edgar Allan Poe termina com uma foto do busto de Poe no Hall of Fame. Veja "Edgar Allan Poe and the Hall of Fame", In: Current Literature 39 (1905): 613-14; e Jay B. Hubbell, Who Are the Major American Writers? (Durham, N.C.: Duke University Press, 1972), 547. 
"Minhas vítimas, se colocadas ponta a ponta, chegariam de Nevada ao Golden Gate"16. O artigo de Starrett multiplicou o número de suas vítimas, mas também multiplicou o número de cópias conhecidas de Tamerlane - mais quatro vieram à luz entre $1925 \mathrm{e}$ 1929, e mais duas apareceram na década de 1930 (apenas mais duas surgiram desde então). Uma cópia foi vendida por US\$25.000 em 1926; outra foi vendida por US\$ 28.500 em 1927 e foi parte de uma venda de uma coleção de Poe que valia US\$50.000 em 1933 ${ }^{17}$. Em 1929, o livreiro Arthur Swann comprou uma cópia recém-descoberta por US\$ 20.00018. O artigo de Starrett e as descobertas e vendas que o seguiram melhoraram a reputação de Poe por terem sido anteriormente subvalorizados, uma vez que preços altos consistentemente eram pagos por livros que atraíam pouca atenção no momento de sua publicação. Claro que os preços de leilão para Poe aumentaram exponencialmente desde a década de 1930. Em 2009, uma das doze cópias conhecidas de Tamerlane foi vendida por US\$662.500; um manuscrito do poema de Poe "For Annie" foi vendido por US\$ 830.500 no mesmo leilão ${ }^{19}$. Em uma entrevista por telefone, Susan Jaffe Tane, cuja coleção de Poe inclui uma cópia de Tamerlane que ela comprou em 1991, afirmou que os manuscritos e as primeiras edições do escritor são sempre mais valiosos do que os de seus contemporâneos americanos, e não apenas pela escassez de oferta ${ }^{20}$. Outro colecionador de Poe, Peter Fawn, concordou: "Sim, acredito que Poe sempre terá um público maior do que a maioria dos escritores do século XIX, simplesmente por causa do assunto sobre o qual ele mais frequentemente escreveu, bem como as circunstâncias trágicas que cercaram sua vida pessoal" (grifo nosso) ${ }^{21}$.

Ao longo do século $X X$, então, o nome de Poe tornou-se sinônimo não apenas de contos de mistério e terror, mas também de vestígios literários de alto preço. Por exemplo, no romance policial de Amelia Reynolds Long, de 1945, Death Looks Down, um manuscrito roubado de "Ulalume", em torno do qual o enredo gira, é avaliado em US\$ 10.000. Um sargento da polícia designado para o caso está confuso, mas impressionado: "Diga, esse cara, Poe, deve ser bom! Ele deveria escrever para Hollywood"22.

A piada, às custas do sargento, depende da expectativa de que os leitores reconheçam que US\$10.000 é um preço razoável para um manuscrito de Poe, e que o

\footnotetext{
${ }^{16}$ Vincent Starrett, "Have Youa Tamerlanein Your Attic?" Saturday Evening Post, 27June 1925, 72.

17 "Tamerlane and Other Poems (1827): Census of Copies", em The Collected Works of Edgar Allan Poe: A Comprehensive Collection of E-Texts, ed. Jeffrey A. Savoye.

18 Ibidem.

19 Christie's: The Art People, Sale 2153, Lots 155 and 171, Auction Results. Disponível em: http://www.christies.com/lotfinder/books-manuscripts/poe-edgar-allan-tamerlane-and-other-5280770-details.aspx. Acesso em: 29 de maio de 2020.

${ }^{20}$ Veja também: TANE (2013), 201-5.

${ }^{21}$ Peter Fawn, mensagem de e-mail para o autor, 4 de março de 2014.

${ }^{22}$ Amelia Reynolds Long, Death Looks Down. Chicago: Ziff Davis, 1945, p. 32.
} 
desconhecimento de seu valor aproximado mostra falta de consciência cultural. Outra história desse período, "The Man Who Collected Poe" (1951), de Robert Bloch, retrabalha "The Fall of the House of Usher" com um colecionador de Poe no papel de Roderick; ele tem um morto-vivo Edgar Poe trancado no porão, escrevendo novos contos "cheios e repletos de um terror que não pode ser aguentado"23. Bloch leva à revelação de um Poe escravo-zumbi sepultado, fazendo com que o colecionador guie $o$ narrador através do objetos mais convencionais de sua coleção, lembrando-o de seu valor: uma cópia de Tamerlane, "que, como você certamente sabe, é hoje avaliada em quinze mil dólares", além de um "pequeno caderno, publicado em 1843 e vendido por doze centavos e meio, intitulado The Prose Romances, de Edgar A. Poe; uma ninharia insignificante contendo duas histórias que são avaliadas pelos colecionadores atuais em cinquenta mil dólares"24. Embora o colecionador (ou Bloch) pareça ter supervalorizado os romances em prosa em relação a Tamerlane, ele não pode exibir esses artefatos sem gabar-se do seu valor de mercado.

Lançado no mesmo ano em que "The Man Who Collected Poe" foi publicado, o filme de Fletcher Markle, The Man with a Cloak, aborda o mito da obscuridade de Poe em seu tempo, contrastando com sua fama em meados do século $X X^{25}$. A epígrafe do filme provoca o público, sugerindo que o personagem-título é alguém que eles deveriam conhecer, seja desconhecido para seus contemporâneos: "Na vida de todos os homens, há momentos de mistério - pois o homem muitas vezes deseja, e às vezes escolhe, vagar sozinho e sem nome. Este é o conto de um viajante assim, outrora pouco conhecido e menos respeitado, cujo nome verdadeiro mais tarde se tornou imortal". O andarilho é, evidentemente, Poe, que usa o pseudônimo "Dupin" ao longo do filme. Ninguém o reconhece, apesar do fato de o filme ser encenado em 1848, três anos após o sucesso de "The Raven", e apesar do fato de que ele se identifica como poeta em vários momentos, e de se em Nova York, onde Poe morava na época. Porque ele escolhe "vagar sozinho e sem nome" permanece um mistério tão grande quanto o motivo de ninguém o reconhecer. The Man with a Cloak tem uma atmosfera e um diálogo nitidamente noir, suavizado de alguma maneira por uma estranha ilustração hollywoodiana de Nova York antebellum; por conseguinte, Joseph Cotten interpreta Poe/Dupin como um detetive amador durão, com Barbara Stanwyck como a femme

${ }^{23}$ Ver: BLOCH (1969: 121). Como Jeffrey Andrew Weinstock sugere em um ensaio recente, a história de Bloch desconstrói a lógica de colecionar: "A fantasia do colecionador é completar. A ressurreição de Poe, no entanto, desfaz Canning não apenas com a revelação de que completude é impossível, mas com a percepção de que a pessoa por trás da função de autor inevitavelmente escapará". Veja WEINSTOCK (2012: 24-25).

${ }^{24}$ BLOCH (1969: 109).

${ }^{25}$ Fletcher Markle (dir.), The Man with a Cloak (MGM, 1951; Warner Archive Collection, 2010). 
fatale, apropriadamente chamada Lorna Bounty. Dupin faz amizade com uma atraente jovem francesa, Madeline Minot (Leslie Caron), que viajou de Paris para pedir a um misantropo moribundo, Charles Thevenet (Louis Calhern), que deixasse sua fortuna ao seu neto, um líder da causa revolucionária (e também seu amante). Isso significaria excluir Bounty e dois outros servos vilões do seu testamento. Dupin não apenas ajuda a convencer Thevenet a escrever o novo testamento - em apoio ao idealismo igualitário e ao amor verdadeiro -, mas também salva o novo testamento da destruição pelas mãos dos pretensos herdeiros imerecidos.

O Poe de The Man with a Cloak é claramente alcoólatra - bebe compulsivamente sempre que há vinho disponível, frequentemente comentando sua dependência - e falido. Na cena de abertura, ele estabelece uma conversa em curso com o taberneiro Flaherty (Jim Backus) sobre a questão de sua capacidade de alguma vez pagar a conta do bar. E, no entanto, como em The Loves, de Edgar Allan Poe, a pobreza e o alcoolismo não aparecem como fraquezas do caráter de Poe. Fiel ao tipo de detetive durão, ele nunca parece bêbado, apesar de beber constantemente. E ele usa sua pobreza como um distintivo de honra, lembrando sardonicamente o Flaherty de cor para quem "o amor ao dinheiro é a raiz de todo mal". Quando subornado por Lorna, ele chama o dinheiro "o corruptor da consciência e da honra; faz de amigos inimigos e de inimigos amigos. Mas, tendo pouco, não sou de falar muito sobre isso". Ele, então, devolve o dinheiro que ela ofereceu. Em uma conversa anterior, Lorna comenta: "Estou começando a pensar que subestimei você", no que Poe responde: "Assim como minha geração". De fato, o filme reivindica Poe contra ter sido subestimado. Ele é honroso o suficiente para ajudar a inocente Madeline e sua nobre causa sem procurar qualquer remuneração; ele é esperto o suficiente para detectar o esquema assassino dos servos e localizar o segundo testamento (escondido, incidentalmente, pelo corvo de estimação de Thevenet); e, apesar de incidental ao enredo, também é um poeta brilhante.

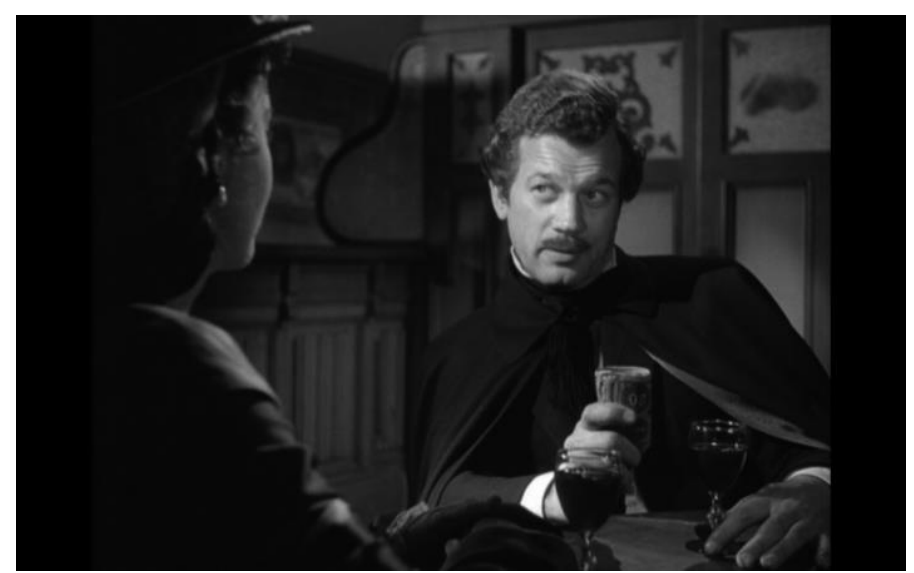

Figura 03 - The Man with a Cloak, 1951. 
Na cena final do filme, quando Madeline chega à taverna procurando por Dupin, Flaherty a informa que seu herói se foi: "Senhorita, eu nem sei quem ele é. Ele me deu um nome e eu dei a ele algum crédito. E ele me deu essa nota promissória com outro nome nela. Ah, você não vai encontrar esse cara. Esse nome nunca valerá nada". Enquanto Flaherty fala, a câmera corta para um manuscrito contendo as primeiras linhas de "Annabel Lee", enquanto a chuva começa a riscar a escrita. "Não daqui a cem anos", conclui Flaherty, enquanto Madeline vira o papel na sua mão, para revelar as palavras "IOU (Ihe devo) / \$ 8,70 / Edgar Allan Poe". Quando o filme termina, a chuva continua riscando o IOU. O momento final revela a identidade de Dupin para o público, mas claramente nem Flaherty nem Madeline reconhecem o nome; representando sua "geração", Flaherty, como Lorna Bounty, subestimou Poe. Sua observação de improviso, "Nem em cem anos", traça a distância (103 anos, na verdade) entre o cenário do filme e seu lançamento, num tempo em que todos os espectadores reconheceriam o valor do nome Edgar Allan Poe e teriam apreço do valor monetário de seu autógrafo no verso de um manuscrito parcial de "Annabel Lee". A chuva, apagando lentamente os escritos de Poe, agrava a ironia da cena final: nem Flaherty nem Madeline valorizam a nota (como um IOU ou como artefato literário) o suficiente para salvá-la da destruição, mas o público pode adivinhar seu valor - pelo menos vários milhares de dólares, em 1951.

Apesar do grande volume de filmes baseados (vagamente) nas histórias de Poe desde a década de 1950, nenhum grande estúdio lançou uma cinebiografia do autor desde The Loves of Edgar Allan Poe, e relativamente poucos filmes de ficção apresentaram Poe como personagem central ${ }^{26}$. Uma grande exceção, o filme de James McTeigue, de 2012, The Raven, atualiza a imagem de Poe como herói azarão ${ }^{27}$ - e aumenta o interesse nela. Como em The Man with a Cloak, Poe tem o papel de um detetive amador, ao qual ele deve ter se acostumado através de vários romances de mistério, incluindo a série de quatro livros de Howard Schechter (começando com

\footnotetext{
${ }^{26}$ Para um inventário de filmes relacionados a Poe até 1992, veja SMITH (1998). Devo observar três representações de Poe em filmes não discutidos neste ensaio: A interpretação de Terence Stamp do personagem-título em "Toby Dammit", de Federico Fellini, o terceiro filme da trilogia Histoires Extraordinaires/Spirits of the Dead (American International Films, 1969), evoca Poe de algumas maneiras, mas sem nenhuma referência direta à biografia de Poe. The Spectre of Edgar Allan Poe (dirigido por Mory Quandour, Cintel Productions, 1974) coloca seu personagem-título em um hospital psiquiátrico administrado por um médico sinistro e sua perturbada esposa homicida, mas, apesar de ter um faturamento superior e tempo de tela amplo, o personagem Poe é subdesenvolvido; embora o filme enquadre seu enredo principal como uma explicação para a obsessão de Poe com "morte, decadência e loucura", a identidade do personagem como Poe é, na maior parte, incidental. E Poe (interpretado por Ben Chaplin) aparece em sequências de sonhos em Twixt (American Zoetrope, 2012) de Francis Ford Coppola, mas ele serve como pouco mais que inspiração para outro personagem e fornecedor de exposição; como em The Spectre of Edgar Allan Poe, seu Poe-ismo faz pouca diferença.

${ }_{27}$ James McTeigue (dir.), The Raven (20th Century Fox/Relativity Media, 2012).
} 
Nevermore, em 1999), Nevermore, de William Hjortsberg (1994), The Pale Blue Eye, de Louis Bayard (2006), e o romance de Avi YA, The Man Who Was Poe (1989). Usando um esquema que lembra o romance de Hjortsberg, o enredo de The Raven passa por uma série de horrendos assassinatos encenados para sugerir histórias de Poe. Inicialmente suspeito de envolvimento nos crimes, Poe (interpretado por John Cusack) é recrutado para ajudar a capturar um serial killer que também sequestrou e enterrou viva a noiva do escritor, Emily Hamilton (Alice Eve).

The Raven apresenta Poe invocando o trocadilho com "pobre". No início do filme, Poe entra em uma taverna lotada e pouco iluminada e imediatamente começa a discutir com o barman. Menos paciente que Flaherty, de The Man with a Cloak, esse taberneiro se recusa a servir Poe, resmungando "Isso vai aproximadamente cobrir a última conta" quando Poe atira violentamente dinheiro no bar para provar sua capacidade de pagamento. Poe, então, descaradamente esvazia a caneca do cliente ao lado dele antes de tentar negociar com o barman: "Eu ganho uma bebida para cada homem aqui que me reconheça, ou um dos meus poemas". Quando essa jogada falha, o bêbado cuja bebida Poe roubou o ameaça, levando Poe a anunciar:

- Sou um poeta nacionalmente elogiado!

- É por isso que você não tem dinheiro.

- Eu sou Poe.

- Foi o que eu disse.

Pedante e arrogante, Poe passa a corrigir o bêbado e procura desesperadamente reconhecimento (recebendo-o apenas de um único cliente francês) antes de ser expulso do bar. McTeigue, junto com os escritores Hannah Shakespeare e Ben Livingston, inicialmente revela abuso de substância por Poe, mesmo tendo o editor do jornal Baltimore Patriot alertado o escritor para largar "a bebida e as tinturas [de ópio] porque está apodrecendo seu cérebro". O Poe de 2012 rapidamente se mostra mais debochado - e acerbo - que o Poe durão de 1951, como ele responde sarcasticamente que só bebe socialmente "para aliviar minha timidez, e as tinturas são puramente terapêuticas, um leve paliativo contra o frio do desespero de um órfão". Quando o pai de Emily, que obviamente quer manter Poe longe de sua filha, o acusa de ser "um alcoólatra, um viciado em ópio e um ateu", Poe se opõe apenas ao último desses rótulos.

Mas o sequestro e os assassinatos presenciados transformam Poe de um poeta alcoólico empobrecido em um herói detetive sóbrio e altruísta. Essa mudança repentina para a sobriedade e o foco mental é típica de histórias de detetive e filmes de Sherlock Holmes em diante; de fato, quando o Poe de Cusack se torna um detetive, ele é absorvido na versão moderna do gênero que Poe originou. Ao mesmo tempo, o desaparecimento dos traços de caráter definidores de Poe do primeiro ato do filme 
sugere que McTeigue precisava que seu público reconhecesse "Poor Poe", mesmo que esse personagem não pudesse ser comparado ao herói de ação que o restante do filme exige. Além de se juntar ao detetive da polícia em sessões de estratégia e perseguição física ao assassino, Poe imediatamente decodifica todas as pistas que seu inimigo deixa, por mais obscuras que sejam.

O vilão, revela-se, é Ivan Reynolds, um fã perturbado que frequentemente encontrava Poe em seu trabalho como tipógrafo no jornal. Tomando emprestada uma página do playbook de Annie Wilkes, em Misery, de Stephen King, Reynolds alega ter cometido esses crimes para inspirar Poe a escrever outro grande mistério horripilante esse com o próprio Poe como protagonista. E ele consegue: Poe segue as instruções do assassino, escrevendo um seriado policial real publicado no Patriot. Poe salva Emily, mas apenas jogando o jogo do assassino, finalmente sacrificando sua própria vida pela dela (ele concorda em beber veneno em troca da pista final que revela sua localização). Assim, Poe finalmente salva a mulher, moribundo - algo que o Poe das cinebiografias era, obviamente, incapaz de fazer - e o faz, pelo menos em parte, publicando seu trabalho. Embora The Raven não termine fazendo alusão ao valor monetário de seu legado literário, ele aponta para a carreira póstuma de Poe como o mestre reconhecido e lucrativo do macabro. Reynolds se vê como um guardião da chama, dizendo a um Poe moribundo que, mesmo quando ele parecia ter ficado sem ideias para seus contos góticos, "eu ainda acreditava na sua visão, em um futuro em que as pessoas ficariam na fila para ver o tipo de coisas que apenas pessoas como você e eu podiam ver... Ninguém jamais esquecerá de você". Claro que, como outros vilões inspirados em Poe - do Dr. Vallon, de Bela Lugosi, em mais um filme intitulado The Raven (1935), até o Prof. Joe Carson, na série de televisão The Following (2013-15) - Raynolds distorceu Poe em sua própria imagem psicótica. E, no entanto, mais uma vez, os cinéfilos reconhecem a profecia nas palavras de Reynolds. Embora The Raven pareça não conseguir decidir como Poe era conhecido em 1849, ele conclui com o contraste reconfortante entre a obscuridade implícita no discurso de Reynolds e a fama póstuma do escritor, um futuro em que "as pessoas ficariam na fila" para compartilhar a "visão" de Poe. Essa última imagem sugere mais filmes do que livros, não apenas porque o público de filmes compartilha literalmente imagens visuais em vez de imaginá-las durante a leitura, mas também porque ficar na fila está mais associado à experiência de cinema do que à compra de livros. E, embora as filas não tenham sido particularmente longas para The Raven, a regularidade com que Poe e seus contos góticos foram referenciados em títulos de filmes sugere que sua "visão" - realmente, nossa visão dele - é uma boa bilheteria. No início dos anos 60, por exemplo, os filmes do "Poe Cycle", de Roger Corman arrecadavam entre US\$ 1 milhão e US\$ 2 milhões em orçamentos de cerca de US\$ 
$200.000^{28}$. Nos cinemas como nas casas de leilão, Poe provou ser um bom investimento: compre Poe, venda caro.

É quase impossível imaginar uma apresentação cinematográfica de Poe que, de alguma forma, não invoque a imagem do poeta alcoólico pobre, não apreciado - e certamente qualquer apresentação que contradiga diretamente essa imagem, retratando Poe como tendo sido bem de vida ou desfrutado celebridade de longa duração, seria incorreta. E, no entanto, facetas importantes da vida e da carreira de Poe tendem a ser negligenciadas nessa linhagem de representações: por exemplo, seu relacionamento frequentemente combativo com outros escritores; sua ambição ao longo da sua carreira de fundar e editar sua própria revista literária; seu momento de fama após a publicação de "The Raven"; seu flerte público com Frances Osgood e a busca posterior e desesperada por outras mulheres após a morte de Virginia; seu genuíno interesse pela ciência, culminando na publicação de Eureka. Não menciono esses elementos que faltam na biografia de Poe para culpar os filmes antigos de Hollywood como The Loves of Edgar Allan Poe ou mesmo os novos como The Raven; não é tarefa deles ser historicamente precisos ou completos. Mas tentei demonstrar que todos esses filmes, biográficos ou manifestamente fictícios, simplificam Poe essencialmente da mesma maneira: como um homem sem sucesso buscando validação para sua poesia (nunca sua prosa); bebendo como resposta à sua frustração, mas nunca se comportando mal enquanto estava bêbado; sacrificando para o benefício de outros; e trabalhando na obscuridade, para ser apreciado somente após sua morte. Inevitavelmente, Poe se torna mártir - para sua esposa (ou, em The Raven [2012], sua substituta) e para a literatura. E Poe se torna martírio, assegurando seu lugar como o eterno forasteiro, amado por não ter sido amado e altamente valioso por ter sido subvalorizado.

\section{Referências}

BLOCH, Robert. "The Man Who Collected Poe". In: The Man Who Called Himself Poe. Ed. Sam Moskowitz. Garden City, N.Y.: Doubleday, 1969. p. 121.

CARLSON, Thomas C. "Biographical Warfare: Silent Film and the Public Image of Poe". In: Mississippi Quarterly 52, no. 1 (1998). p. 5.

CORMAN, Roger; JEROME, Jim. How I Made a Hundred Movies in Hollywood and Never Lost a Dime. New York: Random House, 1990. p. 78-84.

DAWKINS, Richard. The Selfish Gene (1976). Oxford: Oxford University Press, 2006. p. 192.

\footnotetext{
${ }^{28}$ Roger Corman, com Jim Jerome, How I Made a Hundred Movies in Hollywood and Never Lost a Dime (New York: Random House, 1990), 78-84.
} 
HAWTHORNE, Julian. "My Adventure with Edgar Allan Poe". In: The Man Who Called Himself Poe. Ed. Sam Moskowitz. Garden City, N.Y.: Doubleday, 1969. p 63.

Jay B. Hubbell. Who Are the Major American Writers? Durham, N.C.: Duke University Press, 1972. p. 547.

JACKSON, David K.; THOMAS, Dwight. The Poe Log. Boston: G. K. Hall, 1987. p. 437.

LANG, Andrew. Letters to Dead Authors (1886). New York: AMS Press, 1968. p. 141144.

LONG, Amelia Reynolds. Death Looks Down. Chicago: Ziff Davis, 1945. p. 32.

MCGILL, Meredith L. American Literature and the Culture of Reprinting, 1834-1853. Philadelphia: University of Pennsylvania Press, 2003.

OSTROM, John W. ; POLLIN, Burton R.; SAVOYE, Jeffrey A. (eds.). The Collected Letters of Edgar Allan Poe. New York: Gordian, 2008.

PEARL, Matthew. "A Poe Death Dossier: Discoveries and Queries in the Death of Edgar Allan Poe”. In: Edgar Allan Poe Review 7, no. 2 (2006): 30-49; e 8, no. 1 (2007): 8-31.

PEEPLES, Scott. “That Name'll Never Be Worth Anything': Poe's Image on Film”. In: The Edgar Allan Poe Review, Vol. 16, No. 2 (Outono 2015), p. 169-183. Disponível em: https://www.jstor.org/stable/10.5325/edgallpoerev.16.2.0169. Acesso em: 15 de janeiro de 2019.

PEEPLES, Scott. The Afterlife of Edgar Allan Poe. Rochester, N.Y.: Camden House, 2004.

QUINN, Arthur Hobson. Edgar Allan Poe: A Critical Biography (1941). Baltimore: Johns Hopkins University Press, 1998. p. 639.

SMITH, Don G. A Critical Filmography of Theatrical Releases Based on the Works of Edgar Allan Poe. McFarland Publishing, 1998.

STARRETT, Vincent. "Have You a Tamerlane in Your Attic?". In: Saturday Evening Post, 27 June 1925, 72.

SAVOYE, Jeffrey A. (ed.). The Collected Works of Edgar Allan Poe: A Comprehensive Collection of E-Texts. Disponível em:www.eapoe.org/works/editions/taop.htm. Acesso em: 11 de junho de 2015.

SMITH, Don G. The Poe Cinema: A Critical Filmography of Theatrical Releases Based on the Works of Edgar Allan Poe. Jefferson, N.C.: McFarland, 1999. p. 18-22.

TANE, Susan Jaffe. "A Poe Collector's Memoir". In: GEWIRTZ, Isaac. Edgar Allan Poe: Terror of the Soul. New York: New York Public Library, 2013).

WEINSTOCK, Jeffrey Andrew. "Edgar Allan Poe and the Undeath of the Author". In: Adapting Poe: Re-imaginings in Popular Culture. (ed. Dennis R. Perry and Carl H. Sederholm). New York: Palgrave Macmillan, 2012. P. 24-25. 